\title{
Experimental Investigations on Creep Behavior of Coal under Combined Compression and Shear Loading
}

\author{
Rongbin Hou $\mathbb{D}^{1,2}$ Leige $\mathrm{Xu}^{1}{ }^{1}$ Duoxin Zhang, $^{1}$ Yanke Shi $\mathbb{D}^{1,2}$ and Luyang Shi ${ }^{1}$ \\ ${ }^{1}$ School of Civil Engineering and Communication, North China University of Water Resources and Electric Power, Zhengzhou, \\ 450045 Henan, China \\ ${ }^{2}$ MWR Center for Levee Safety and Disease Prevention Research, Yellow River Institute of Hydraulic Research, \\ Zhengzhou 450003, China
}

Correspondence should be addressed to Rongbin Hou; hourongbin@ncwu.edu.cn and Yanke Shi; shiyanke@ncwu.edu.cn

Received 15 March 2021; Accepted 16 August 2021; Published 30 August 2021

Academic Editor: Yi Xue

Copyright (c) 2021 Rongbin Hou et al. This is an open access article distributed under the Creative Commons Attribution License, which permits unrestricted use, distribution, and reproduction in any medium, provided the original work is properly cited.

\begin{abstract}
The creep behavior of rock has received much attention for analyzing the long-term response and stability of underground rock engineering structures. Numerous studies have been carried out on the creep properties of various rocks under pure compression conditions. However, little attention has been paid to the creep behavior of rocks in a combined compression-shear loading state. In this work, a novel combined compression and shear test (C-CAST) system was used to carry out inclined uniaxial compression tests and creep tests for various inclination angles $\left(0^{\circ}, 5^{\circ}, 10^{\circ}\right.$, and $\left.15^{\circ}\right)$. The results revealed that the peak strength of the coal decreased with the inclination angle of the specimen, which could provide the basis for setting up a creep test scheme. Multistage compression-shear creep tests were carried out on specimens with different inclination angles. Based on the analysis of the creep test data, the creep behavior of the coal in a combined compression-shear state was studied. It was found that the specimen inclination affected the time-dependent deformation, long-term strength (LTS), and time to failure. Compared with the specimen under pure compression, the inclination specimens tend to produce large shear strain with time, while they were more prone to shear failure. The reduction of the long-term strength was closely associated with the increase of the specimen inclination angle when the angle was more than $5^{\circ}$. Moreover, the ratio of the peak strength to the LTS was not affected by the specimen inclination, which is considered an inherent characteristic. We anticipate that the results obtained will assist in pillar design and long-term stability analysis.
\end{abstract}

\section{Introduction}

Pillars are common rock structures in underground coal mining that are used to control ground subsidence $[1,2]$, protect a roadway [3-5], and isolate the underground water in a goaf [6-8]. The reasonable design of a coal pillar to ensure its long-term stability is the prerequisite for underground disaster prevention and ground-surface environment protection. Previous studies on the long-term stability of coal pillars have mostly assumed that the rock structures are in a pure compression loading condition [9-11]. Then, the uniaxial compressive strength (UCS) of coal is incorporated into the formula of the coal pillar strength estimation. However, the axes of the pillars are usually not parallel to the direction of maximum in situ principal stress in mining practices, such as the loading condition of coal pillars in an inclination coal seam. In this case, if the UCS of the rock is substituted into the strength formula of the inclination pillars, the strength of the coal pillar will be overestimated $[12,13]$. Pariseau [14] and Foroughi and Vutukuri [15] have noted in their studies that the estimation of the pillar stability in an inclination coal seam becomes complicated based on whether or not the rock structures are in a compression-shear loading condition. Furthermore, some researchers have pointed out that the instability of pillars is also related to the creep behavior of rock [16-18]. For example, Yang et al. [17] pointed out that the creep behavior of rock cannot be ignored in the design of a coal pillar, as evidenced by a creep test and numerical analysis. Hence, a detailed understanding of the creep behavior of coal in a combined compression-shear 
loading condition is very important in mining, since it helps in the long-term stability analysis of coal pillars.

Creep is a phenomenon in which the deformation of solid materials increases with time under constant stresses below their peak strength. In order to better understand the long-term creep stability of coal pillars in mining projects, numerous creep experiments for coal have been performed in laboratories, and creep models have been put forward. Chen et al. [16] carried out a uniaxial creep test on coal from the Daizhuang Coal Mine in Shangdong, China, to acquire the initial creep stress and long-term strength of the coal for the long-term stability analysis of a coal pillar. Zhao et al. [19] conducted a triaxial creep test to analyze the effect of the creep load level on a timedependent deformation. The results showed that the transient creep and the steady-state creep were obviously affected by the creep load, and the steady-state creep rate depended on the properties of the coal, the creep load, and the confining pressure. Cai et al. [20] analyzed the hardening damage mechanism of lean coal creep based on the phenomenon for which the instantaneous elastic modulus increased and the viscosity coefficient decreased in the uniaxial compression creep tests. Yang et al. [21] proposed a nonlinear viscoelastic and acceleration creep model of coal based on triaxial creep experiment results at various deviatoric stress levels, which could describe the complete creep stage of coal.

From the abovementioned studies, it is clear that a large number of research conclusions about creep can be well applied on the loading mode of uniaxial compression or triaxial compression. However, few researchers have investigated the time-dependent deformation and long-term strength of coal with a combined compression and shear loading condition. In recent years, the short-term strength, deformation, and microcrack fracturing behaviors of various rocks have been experimentally investigated for dynamic or quasistatic compression-shear loading conditions [12, 22, 23]. For example, Xu and Dai [23] analyzed the mechanical responses of brittle rocks with dynamic compression-shear loading by using a modified split Hopkinson pressure bar (SHPB) system. The results showed that the elastic modulus and the shear modulus were affected by the specimen inclination, and they exhibited loading-path insensitivity for high loading rates. He et al. [12] developed a C-CAST system to study the quasi-static mechanical properties and failure patterns of various rocks with a compression-shear loading condition. The experimental results indicated that both the elastic modulus and the peak strength of the rocks declined as the inclination angle of the specimens increased, and the rocks were prone to shear failure.

Previous studies have shed some light on the influence of specimen inclination perturbation on the short-term mechanical properties of rocks, and many efforts have been devoted to investigating the creep behavior of rocks via the uniaxial or triaxial compressive creep tests as well. Therefore, these findings can provide a good foundation for researching the creep behavior of coal with compressionshear loading. In this research, a series of combined compression-shear loading tests were performed first using the novel C-CAST system. The influence of the coal speci- men inclination on the peak strength for compressionshear loading was studied. The results will provide guidance for the design of a compress-shear loading creep test scheme. Then, creep experiments were conducted under combined compression and shear loading conditions to investigate the effects of the specimen inclination on the timedependent behavior. Additionally, the relationship between the long-term strength and peak strength under combined compression-shear loading conditions was obtained. Finally, the experimental results were discussed in terms of reducing the risk of coal pillar instability in mining engineering.

\section{Experiments}

2.1. Specimen Preparation. The experimental material used throughout this study was coal, which was collected from the Yuandian Coal Mine in Anhui Province, China. In order to maintain the consistency of the specimens, the coal specimens were cored parallel to the bedding of coal seam at the same construction site and wrapped in plastic sheets to prevent moisture loss. Then, according to the recommendation of the International Society for Rock Mechanics (ISRM), all of the specimens were prepared as cylinders with a diameter of $50 \mathrm{~mm}$ and precision ground to $100 \pm 0.02 \mathrm{~mm}$ in length [24], as shown in Figure 1.

All of the prepared specimens for the experiments in this study needed to undergo strict screening. The specimen screening process was as follows. First, the specimens that had obvious flaws (cracks, pores, and inclusions) on the surface (Figure 1) were excluded. Then, the degree of uniformity among the remaining rock specimens was determined based on the measured P-wave velocity and density of the specimens. As a result of the obvious bedding effect of the wave velocity on the coal specimens [25], the P-wave velocity was measured along with two different diametrical directions and axial directions. The arrangement of ultrasonic transducers on a coal specimen for measuring the $\mathrm{P}$-wave velocity is shown in Figure 2. The average values of the Pwave velocities in the axial direction and the diametrical direction for the specimens were $1537.52 \mathrm{~m} / \mathrm{s}$ and $1354.78 \mathrm{~m} / \mathrm{s}$, respectively. The average density of the specimens was $1453 \mathrm{~kg} / \mathrm{m}^{3}$. In view of the $\mathrm{P}$-wave velocity and density being closely related to the strength of the material [26], the specimens with densities from 1453 to $1453 \mathrm{~kg} / \mathrm{m}^{3}$ and with deviation of wave velocities less than $5 \%$ were selected for the subsequent tests.

2.2. Experimental Apparatus and Procedure. The tests were performed at room temperature $\left(25^{\circ} \mathrm{C}\right)$ using the servohydraulic mechanic testing system and the novel C-CAST system at the China University of Mining and Technology. The servohydraulic rock mechanic testing system allowed a maximum axial loading of $1000 \mathrm{kN}$. The axial displacement was automatically recorded by the system. The C-CAST system was originally designed by Fidelis T. Suorineni in cooperation with the University of New South Wales, Australia [12]. Then, He et al. [10] modified the C-CAST system and obtained some valuable research results. In this study, the modified C-CAST system was installed in the 


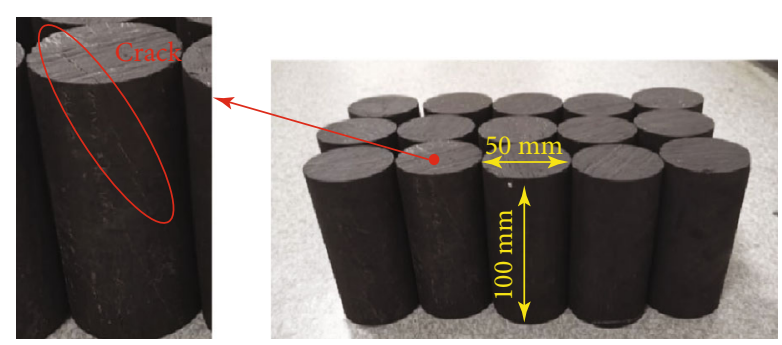

FIgURE 1: A selection of the coal specimens.

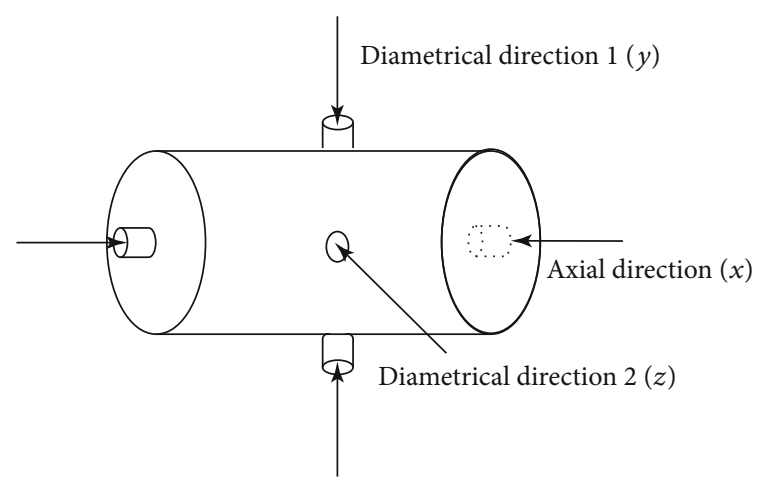

Figure 2: Arrangement of ultrasonic transducers on the coal specimen.

servohydraulic Rock Mechanics Testing System, which could conduct cylindrical specimen inclination loading experiments. The external loading force was applied by the servohydraulic rock mechanic testing system to the adaptors of the C-CAST system. The specimen and the loading diagram of the C-CAST device are shown in Figure 3. The vertical displacement and the loading force of the specimen could be monitored during the tests. Based on the monitoring data and the mechanical analysis, the axial stress, shear stress, axial strain, and shear strain of the specimen under combined compression-shear loading condition were obtained (see Section 2.3).

Understanding the compressive strength and deformation characteristic of rocks is the basis of designing rock creep tests. Therefore, obtaining the peak strength of specimens under compression-shear loading condition is the premise of subsequent creep tests. In this study, the uniaxial compression tests of specimens with four inclined angles were carried out. The inclination angle in this study was set to $0^{\circ}, 5^{\circ}, 10^{\circ}$, and $15^{\circ}$. The modified C-CAST system was loaded at a velocity of $0.3 \mathrm{~mm} / \mathrm{min}$ for all the tests in this study. Five specimens were taken for testing in each test scenario. After the tests, the results that had the highest and lowest vertical peak load values in each test scenario were excluded, and then the peak values of the vertical load were obtained from the remaining three test results. The average values of the peak load for different test scenarios were 34, 31,21 , and $16 \mathrm{kN}$, which could be used to determine the loading level in the subsequent creep tests.

After the compression-shear tests, creep tests were conducted on the specimens with inclination angles of $0^{\circ}, 5^{\circ}$,

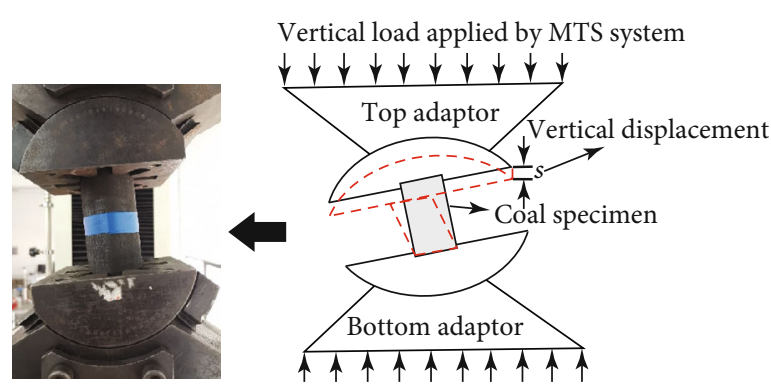

Figure 3: Specimen and loading diagram of C-CAST.

$10^{\circ}$, and $15^{\circ}$ with multilevel loading. In the creep tests, six creep loading stages were set up, and the vertical loading increment (Figure 3) from one level to the next was $4 \mathrm{kN}$. The vertical loading levels in the compression-shear creep tests are shown in Figure 4. Each loading level was maintained for $21600 \mathrm{~s}$, except for the last step (at which point the specimens failed).

2.3. Data Processing. For the case of the conventional uniaxial compressive test and the uniaxial creep test, the specimen was in a pure compression state. The deformation state of the specimen before and after loading is shown in Figure 5. Then, the axial stress and strain of the specimen could be obtained from the following equations:

$$
\sigma_{0}=\frac{F_{v}}{A_{0}}, \varepsilon_{0}=\frac{S}{L},
$$

where $\sigma_{0}$ and $\varepsilon_{0}$ are the axial stress and axial strain of the specimen, respectively, $F_{v}$ and $S$ are the load and displacement signals output directly from the rock mechanic testing system, respectively, and $A_{0}$ and $L$ are the initial crosssectional area and the axial length of the cylindrical specimen, respectively. Based on the laboratory tests and the above theoretical formulas, the mechanical properties of rock under uniaxial loading condition could be evaluated.

In this study, the specimen was obliquely installed on the C-CAST system with a certain inclination, and it was not in pure compression state after loading (i.e., a compressionshear state). Hence, the above equation (1) was no longer applicable for calculating the stress and deformation of the specimen for the compression-shear loading condition. In order to gain insight into the stress and deformation characteristics of the inclined specimen with the vertical loading condition (i.e., the specimen in the compression-shear state), it was necessary to propose a new data processing algorithm based on the experimental monitoring data.

Figure 6 shows the deformation shape of the specimen with the inclination angles of $0^{\circ}, 10^{\circ}$, and $15^{\circ}$ after the quasistatic compression-shear loading tests. From the figure, it can be noted that the deformation behavior of the specimen in the compression-shear loading test was obviously different from that in the pure compression tests. The cylindrical specimen showed axial compression and lateral expansion in the pure compressive state. However, there was a shear slip surface in the specimen in the compression-shear loading 


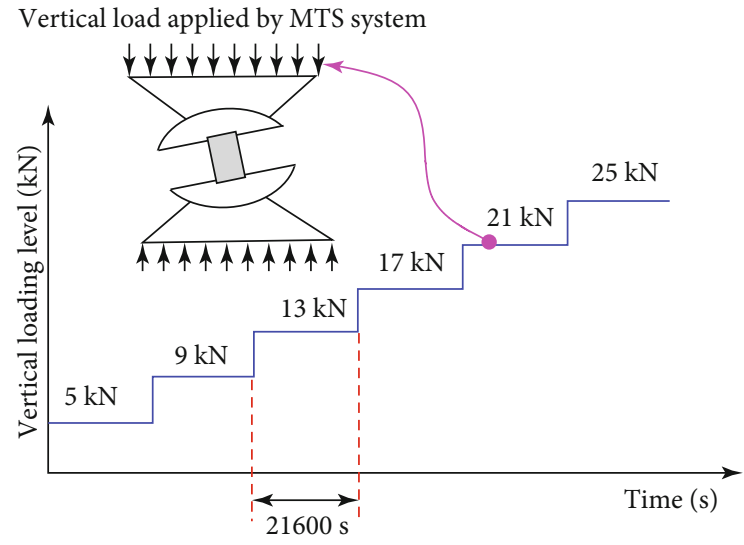

Figure 4: Creep loading levels conducted on the C-CAST system.

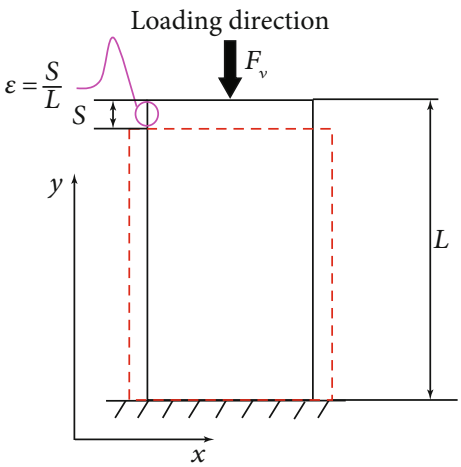

FIGURE 5: Deformation state of the cylindrical specimen in pure compression loading.

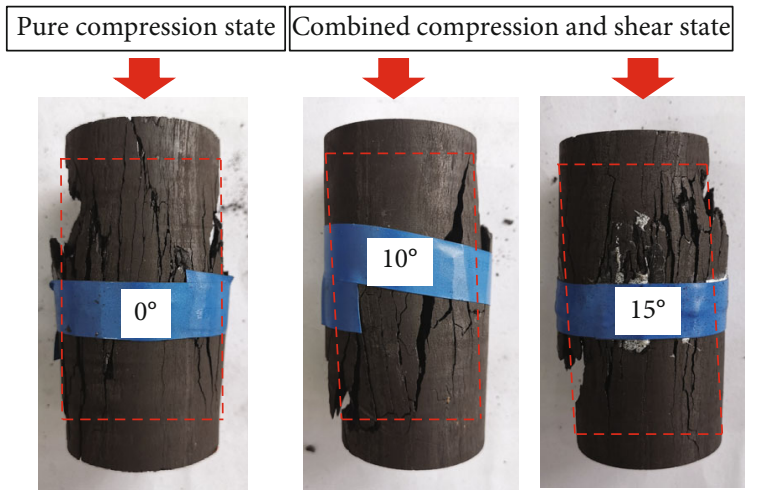

Figure 6: Deformation shape of the specimen at different inclination angles after the quasistatic compression-shear loading tests.

state. Thus, it could be concluded that the mechanical properties and the deformation behavior of the inclination specimen might be closely related to the shear stress component. According to the compression-shear loading test approach, the force analysis was sketched as shown in Figure 7 based on the small deformation hypothesis. The vertical loading force was decomposed to obtain the axial force $\left(F_{n}\right)$ and the shear force $\left(F_{s}\right)$ applied on the contact surface of the specimen. Additionally, after a certain vertical displacement

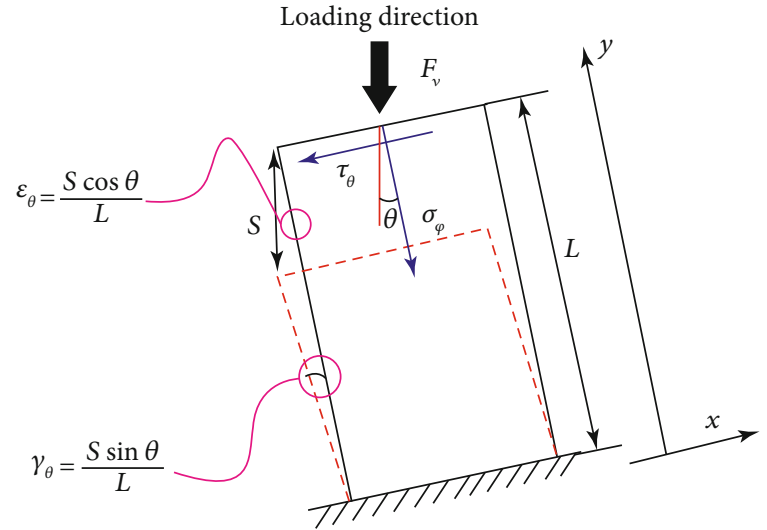

FIGURE 7: Sketch of force analysis of the specimen for the compression-shear loading condition.

$(S)$ on the adaptor of the C-CAST system, there was some compressive and shear deformation. Hence, based on the above analysis, the axial stress and strain as well as the shear stress and strain could be calculated with the following equations:

$$
\begin{gathered}
\sigma_{\theta}=\frac{F_{n}}{A_{0}}=\frac{F_{v} \cos \theta}{A_{0}}, \tau_{\theta}=\frac{F_{s}}{A_{0}}=\frac{F_{v} \sin \theta}{A_{0}}, \\
\varepsilon_{\theta}=\frac{S \cos \theta}{L}, \gamma_{\theta} \approx \tan \gamma_{\theta}=\frac{S \sin \theta}{L},
\end{gathered}
$$

where $\theta$ denotes the inclination angle of the specimen on the C-CAST system, $\sigma_{\theta}$ and $\tau_{\theta}$ are the axial stress component and the shear stress component of the specimen, respectively, and $\varepsilon_{\theta}$ and $\gamma_{\theta}$ are the axial strain and shear strain, respectively.

\section{Experimental Results}

3.1. Influence of Specimen Inclination on Peak Stress. As pointed out in Section 2.2, the peak stresses of the coal specimens at the inclination angles of $0^{\circ}, 5^{\circ}, 10^{\circ}$, and $15^{\circ}$ were analyzed before the creep tests. According to equations (2) and (3), the axial stress, axial strain, shear stress, and shear strain of the inclination specimens were calculated. Then, the stress-strain curves of the specimens at various inclination angles were obtained, as shown in Figure 8. From the figure, it can be seen that the deformation characteristics of the coal samples at different inclination angles were basically the same. These deformation characteristics could be successively divided into the crack compaction, elasticity, yielding, and post peak failure stages. However, the peak strength and strain of the specimens with different inclination angles showed great diversity. As a whole, the peak strength and strain decreased with the increase of the inclination angle, but this law was not obvious when the inclination angle was in the range of $0^{\circ}-5^{\circ}$.

Based on the vertical force data at the peak point of loading curves, the corresponding compression stress and shear stress (i.e., the peak stress) of each specimen were calculated, 


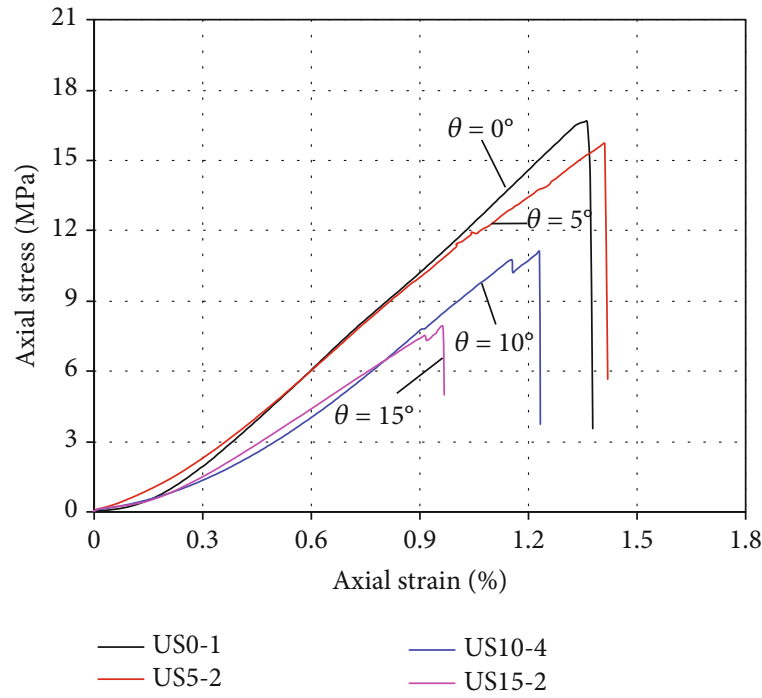

(a)

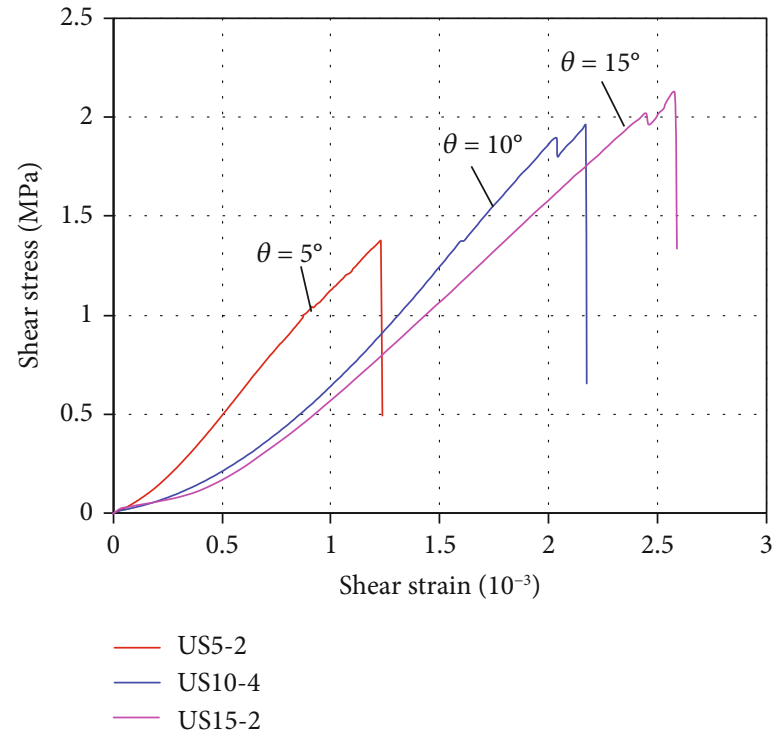

(b)

FIGURE 8: Stress-strain curves of the coal specimen at various inclination angles for the compression-shear loading condition.

TABle 1: Compression stress and shear stress of specimens corresponding to the peak points.

\begin{tabular}{|c|c|c|c|c|c|}
\hline $\begin{array}{l}\text { Test } \\
\text { scenario }\end{array}$ & $\begin{array}{l}\text { Specimen } \\
\text { number }\end{array}$ & $\begin{array}{l}\text { Axial } \\
\text { stress } \\
(\mathrm{MPa})\end{array}$ & $\begin{array}{l}\text { Shear } \\
\text { stress } \\
(\mathrm{MPa})\end{array}$ & $\begin{array}{c}\text { Mean value } \\
\text { of axial } \\
\text { stress } \\
(\mathrm{MPa})\end{array}$ & $\begin{array}{l}\text { Mean value } \\
\text { of shear } \\
\text { stress (MPa) }\end{array}$ \\
\hline \multirow{3}{*}{$\theta=0^{\circ}$} & US0-1 & 16.21 & 0 & \multirow{3}{*}{16.65} & \multirow{3}{*}{0} \\
\hline & USO-2 & 17.15 & 0 & & \\
\hline & US0-4 & 16.59 & 0 & & \\
\hline \multirow{3}{*}{$\theta=5^{\circ}$} & US5-2 & 15.57 & 1.36 & \multirow{3}{*}{15.72} & \multirow{3}{*}{1.36} \\
\hline & US5-3 & 16.69 & 1.46 & & \\
\hline & US5-5 & 14.45 & 1.26 & & \\
\hline \multirow{3}{*}{$\theta=10^{\circ}$} & US10-1 & 11.46 & 2.02 & \multirow{3}{*}{10.81} & \multirow{3}{*}{1.90} \\
\hline & US10-4 & 11.12 & 1.96 & & \\
\hline & US10-5 & 9.86 & 1.73 & & \\
\hline \multirow{3}{*}{$\theta=15^{\circ}$} & US15-1 & 8.45 & 2.26 & \multirow{3}{*}{8.14} & \multirow{3}{*}{2.18} \\
\hline & US15-2 & 7.91 & 2.12 & & \\
\hline & US15-4 & 8.05 & 2.16 & & \\
\hline
\end{tabular}

as listed in Table 1. The relationships between the average peak stresses and inclination angles of the specimens are shown in Figure 9. We concluded that the inclination angle had some effect on the peak stresses of the coal specimens. According to the comparison of the compression strength for uniaxial compressive condition, the peak compression stress of the specimen at the inclination angles of $5^{\circ}, 10^{\circ}$, and $15^{\circ}$ decreased by approximately $5.59 \%, 35.08 \%$, and $51.11 \%$, respectively. When the inclination angle was greater than $5^{\circ}$, the peak compression stress decreased linearly with the increase of the inclination angles. Moreover, it can be seen from Figure 9 that with the increase of the inclination angle of the specimen, the peak shear stress in the specimen

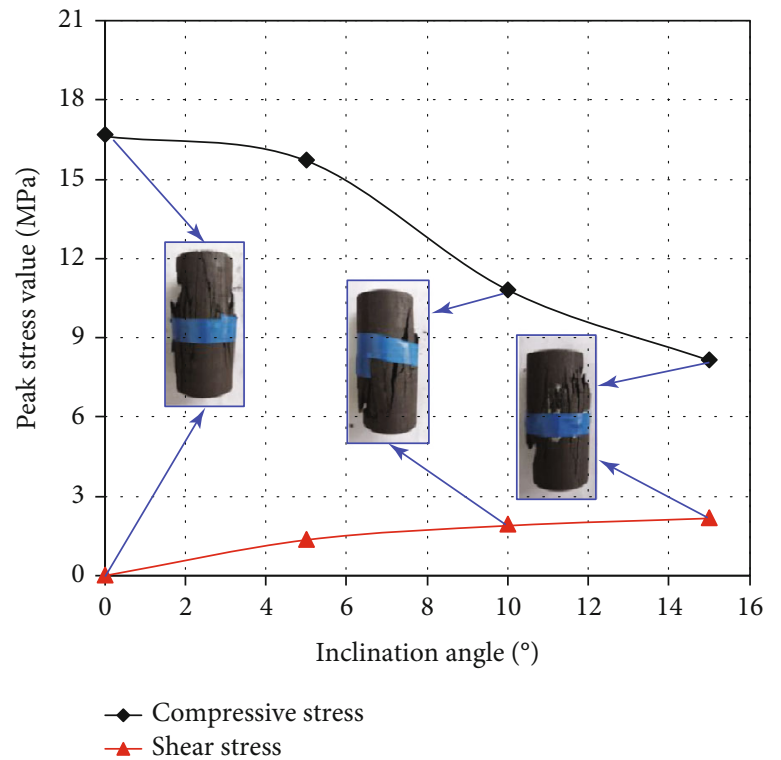

FIGURE 9: Relationship between specimen inclination and peak stress.

increased gradually, and the failure pattern of the rock changed from splitting failure to shear failure.

3.2. Influence of Specimen Inclination on Time-Dependent Deformation. According to the creep test procedure described in Section 2.2, the variation of the axial and shear strains with time for the coal specimens with various inclination angles was plotted, as shown in Figure 10. It can be seen from the figure that the strain-time curves were smooth without fluctuation, which indicated that the deformation had good continuity with time. The deformation of the specimens included the instantaneous deformation in a sudden manner after the application of the load and the time- 


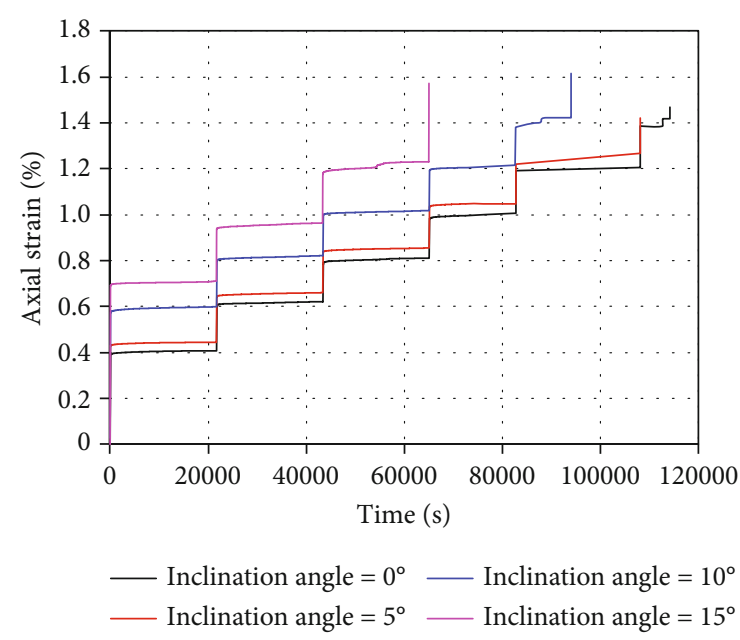

(a) Axial strain-time curve

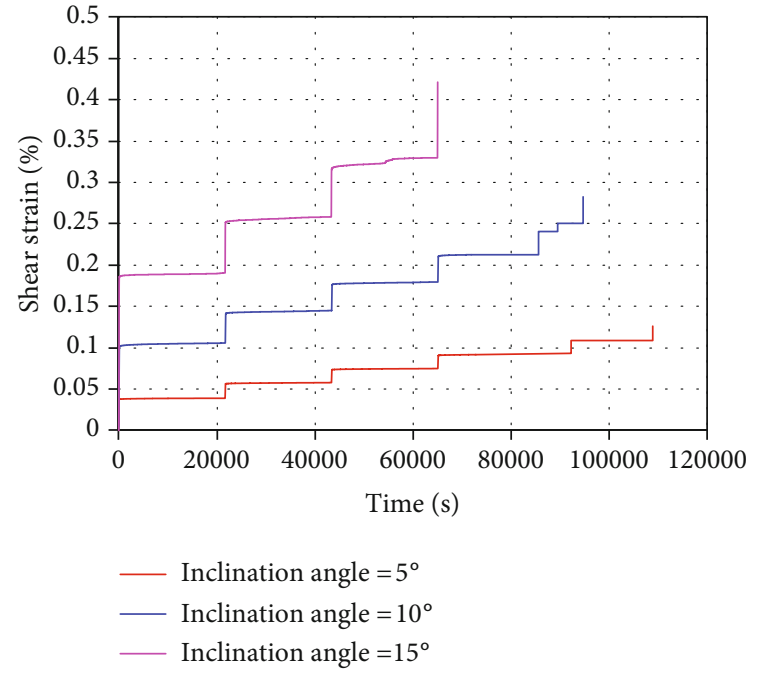

(b) Shear strain-time curve

FIGURE 10: Strain-time curves of specimens with different inclination angles.

dependent deformation with the constant loading condition. Further, compared with the conventional uniaxial creep test (when the inclination angle was $0^{\circ}$ ), the specimens with a combined compression-shear condition seemed to be more prone to creep failure. The test results indicated that the duration of the creep for the coal specimens was significantly affected by the inclination angle for the same test scenario. For example, the durations of creep for the specimens with inclination angles of $0^{\circ}, 5^{\circ}, 10^{\circ}$, and $15^{\circ}$ before specimen failure were $113764,108634,93496$, and $65034 \mathrm{~s}$, respectively. It could be deduced that the failure of the coal pillars was affected by the inclination angle of the coal seam. In deep coal pillar design and long-term stability analysis, the influence of the coal pillar inclination angle on the overall structural safety cannot be ignored.

According to the results of the multistage loading creep tests, the axial creep curves of the coal specimens with different inclination angles at each creep loading levels were obtained by using the Boltzmann superposition principle [27-29]. These curves are shown in Figure 11. It can be found from the figure that the axial creep strain increased over time under constant loading. The creep curves of the coal specimens clearly showed that the time-dependent behavior was related to the levels of the external load. At low creep stress levels (i.e., the first creep stress level in this study), there were only primary creep stages in which the strain rates gradually decreased to zero with time. With the increase of the creep load, the timedependent deformation could be divided into two stages, a primary creep and a steady creep with a constant strain rate. At the final creep stress levels, three creep stages were exhibited, and the coal specimens failed after the tertiary creep stage of the accelerating strain rate. Additionally, it should be pointed out that the tertiary creep did not appear in the creep tests for specimens with inclination angles of $5^{\circ}$ and $15^{\circ}$, which might have been due to the short duration of each creep level.
3.3. Influence of Specimen Inclination on Long-Term Strength. Many studies have shown that the strength of a rock mass with a long-term load is lower than its peak strength, and the instability of a rock structure shows obvious time correlation [30-32]. The long-term strength (LTS) of rock is a mechanical parameter reflecting the time-dependent characteristics, which plays a key role in the long-term stability analysis and life prediction of a rock structure [33-35]. At present, the methods used to determine the long-term strength of rock are mature, including the isochronous stress-strain curves method, the transition creep method, and the steady creep rate inflection point method. Among these methods, the isochronous stressstrain curves method is the most widely used method for determining the LTS of rock. Therefore, this method was used to identify the LTS of coal for different combined compression-shear states in this study.

The isochronous stress-strain curves reflected the variation of the creep stress and strain at the same duration. It should be pointed out that the inflection points of the isochronous stress-strain curves indicated the transformation of the deformation characteristics from viscoelasticity to viscoplasticity. Moreover, the accumulation of viscoplastic deformation with time would eventually lead to rock failure. Therefore, the stress corresponding to the inflection point of an isochronous stress-strain curve is generally defined as the LTS of rock [34-36]. In this study, for the sake of acquiring the LTS of coal specimens with different combined compression-shear conditions, the isochronous stress-strain curves (Figure 12) were drawn based on the process introduced by Tan [37].

As shown in Figure 12, the inflection point of the isochronal stress-strain curve was not evident with the limited test data and short test duration. However, the stress range of the inflection point of the isochronal curve could be obtained according to the creep stress levels. It can be seen from Figure 12 that the stress range of the LTS identified 


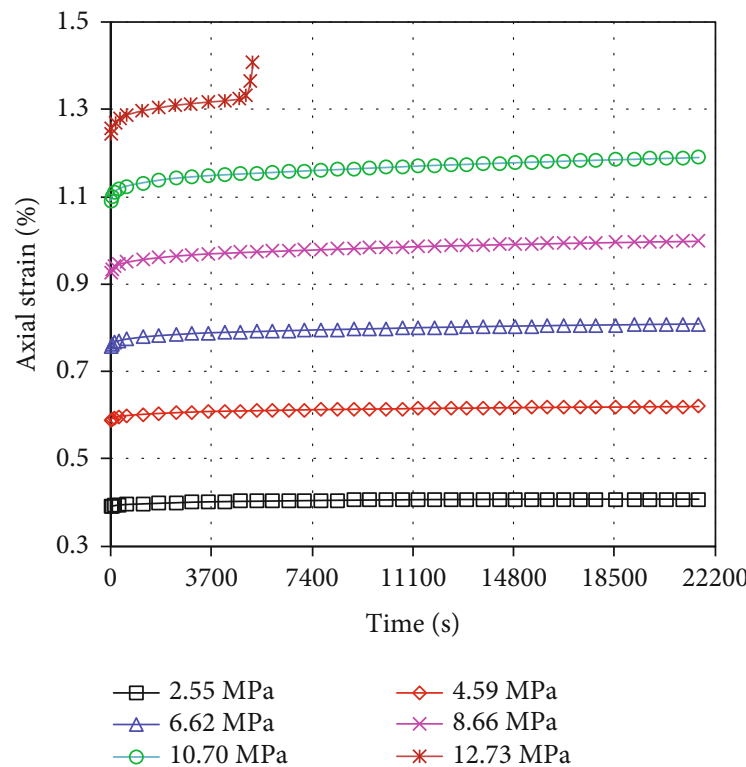

(a) $\theta=0^{\circ}$

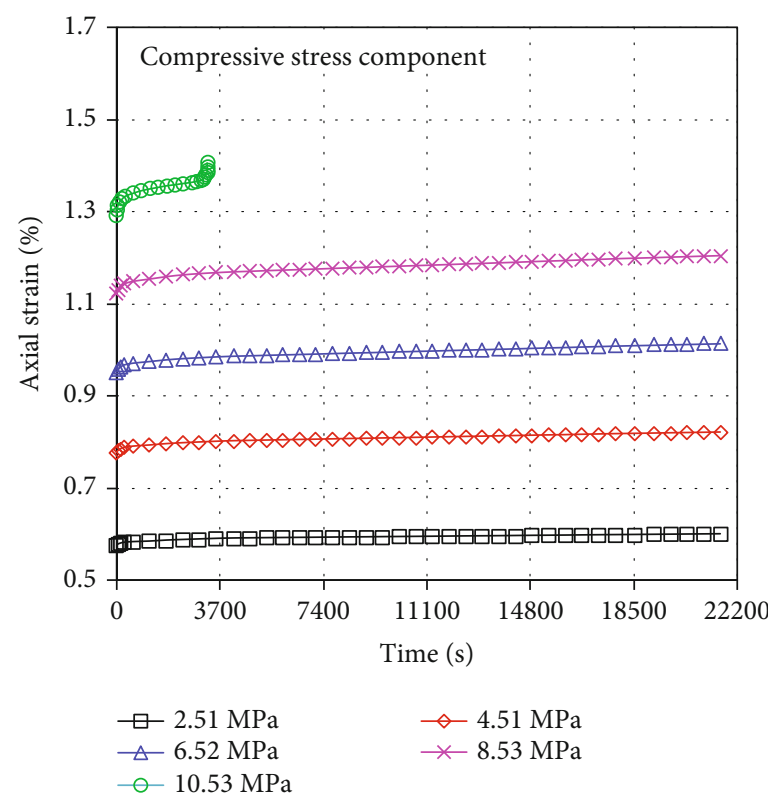

(c) $\theta=10^{\circ}$

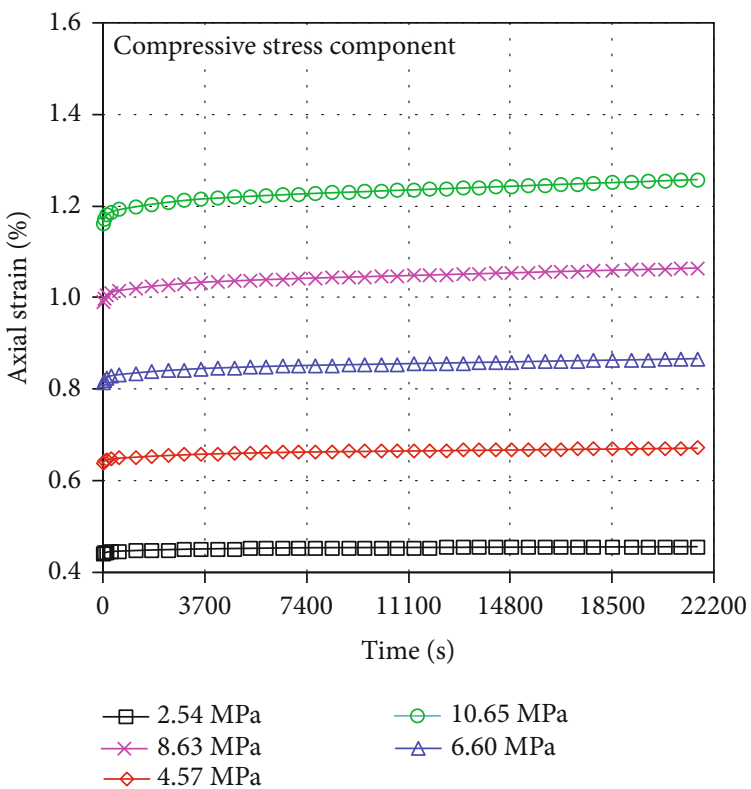

(b) $\theta=5^{\circ}$

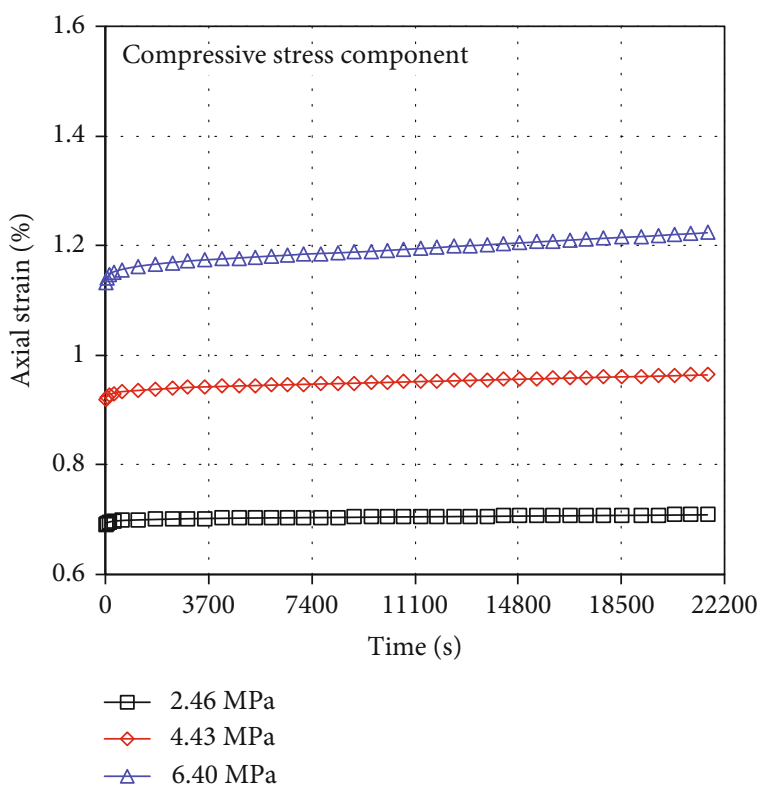

(d) $\theta=15^{\circ}$

Figure 11: Axial creep curves of specimens with different inclination angles $(\theta)$ under compression-shear condition.

from the isochronous stress-strain curves was small. Thus, in order to quantitatively obtain the LTS of the coal for different combined compression-shear conditions, the average values of the stress range could be used as the LTS, and these values were 9.68, 9.64, 7.525, and $5.415 \mathrm{MPa}$, respectively. Figure 13 shows the relationship between the inclination angle of the specimens and the LTS of the coal. It can be seen that the LTS of coal decreased with the increase of the inclination angle. However, when the inclination angle of the specimen was less than $5^{\circ}$, the attenuation of the LTS was not obvious. When the inclination angle increased from $0^{\circ}$ to $5^{\circ}, 10^{\circ}$, and $15^{\circ}$, the LTS of the coal decreased by $0.41 \%$, $22.26 \%$, and $44.06 \%$, respectively. It should be noted that the LTS of the coal specimen decreased noticeably if the specimen inclination was more than $5^{\circ}$.

The peak strength and the LTS of coal specimens with different inclination angles for the combined compressionshear loading condition are listed in Table 2. Moreover, the ratio of the peak strength to the LTS of the specimen under pure compression state was $55.41 \%$, and the ratios of the inclined specimens in a combined compression-shear state were $61.32 \%, 66.53 \%$, and $66.52 \%$, respectively. The relationship between the peak strength and the LTS of the specimens in a combined compression-shear state seemed not to be affected by the specimen inclination angle. Therefore, this meant that if the ratio of the peak strength to the LTS of the 


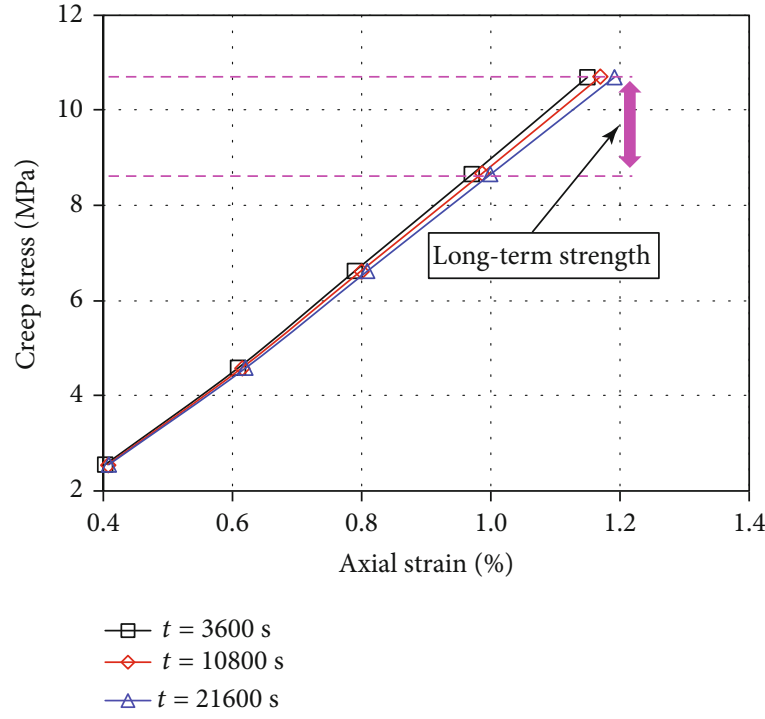

(a) $\theta=0^{\circ}$

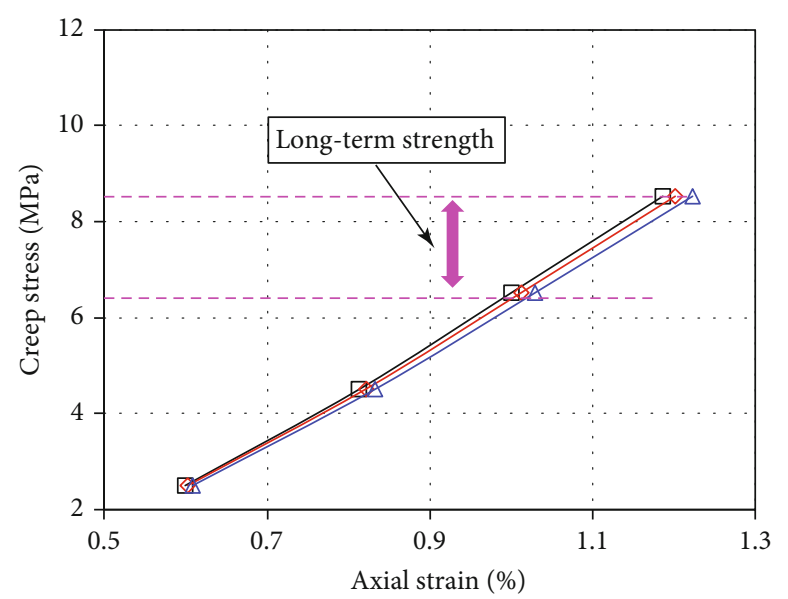

$\begin{aligned} \square & =3600 \mathrm{~s} \\ \neg t & =10800 \mathrm{~s} \\ \neg t & =21600 \mathrm{~s}\end{aligned}$

(c) $\theta=10^{\circ}$

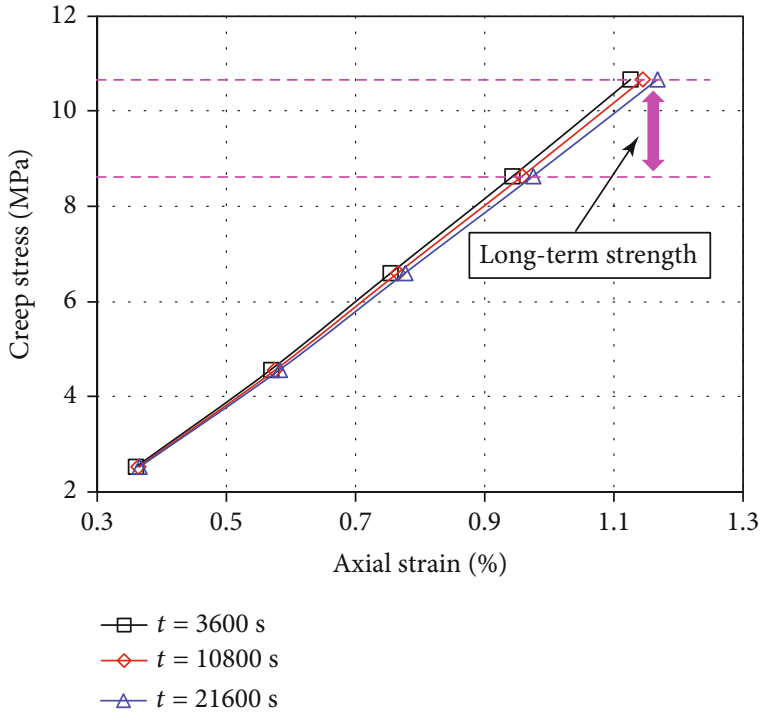

(b) $\theta=5^{\circ}$

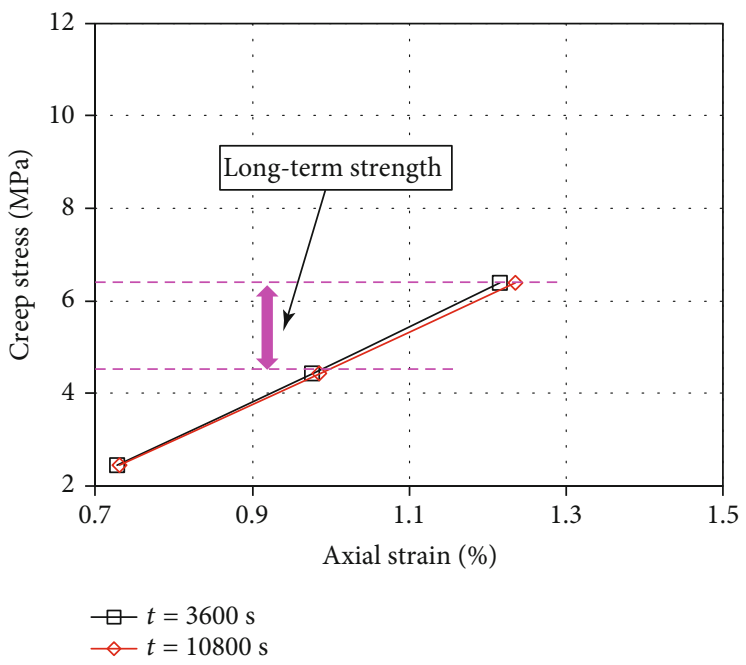

(d) $\theta=15^{\circ}$

FIGURE 12: Isochronous stress-strain curves of coal specimens with different inclinations.

rock in a combined compression-shear state had been determined, the LTS of the rock specimens at any inclination angle could be estimated using the corresponding peak strength.

\section{Implications for Mining Engineering}

During the design and construction of underground engineering, understanding the creep behavior of rock is very important when evaluating the stability of rock construction, such as for deep rock pillars, underground oil or gas storage projects, and nuclear waste repositories. It is worth noting that these rock structures are commonly not in a pure compression state, such as the coal pillar in an inclined coal seam. However, it is very common to analyze the strength of a coal pillar based on the mechanical parameters obtained from a uniaxial compression test or creep test. Obviously, the inclination angle of a coal pillar is ignored when estimating the strength of the coal pillar based on this method. In fact, the coal pillar is in a combined compression-shear loading condition. Therefore, it can be inferred that if only the mechanical properties of rock under pure compression are analyzed to guide the underground rock engineering, then the design is not comprehensive.

In this research, we studied the influence of a combined compression-shear load on the creep behavior of coal via the uniaxial loading creep test of coal specimens with different inclination angles. The results obtained from these tests are useful for better understanding the deformation and creep failure of the coal pillar in an inclined coal seam under constant stress. It could be concluded from these test data that the angles between the axes of the coal pillars and the 


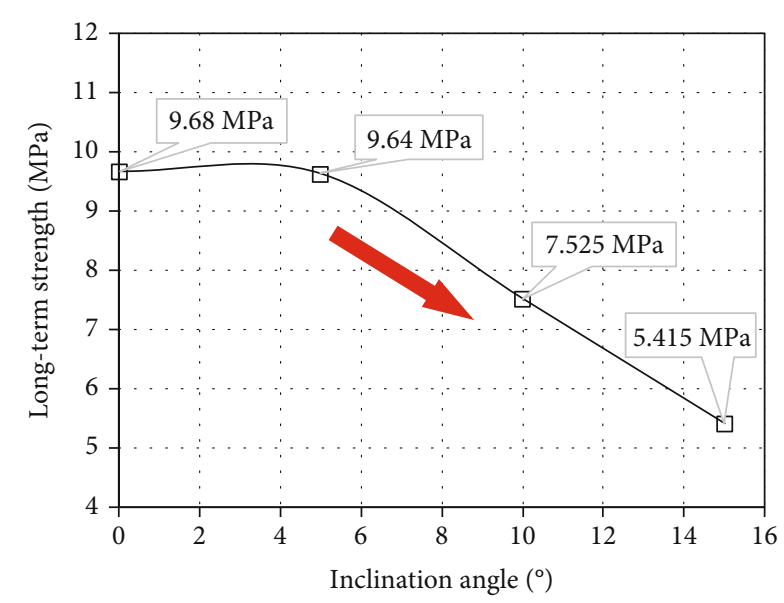

Figure 13: Relationship between inclination angle of specimens and long-term strength of coal in combined compression-shear condition.

TABle 2: Peak strength (PS) and LTS of coal for different compression-shear states.

\begin{tabular}{lccc}
\hline $\begin{array}{l}\text { Inclination angle } \\
\left(^{\circ}\right)\end{array}$ & $\begin{array}{c}\text { Peak strength } \\
(\mathrm{MPa})\end{array}$ & $\begin{array}{c}\text { LTS } \\
(\mathrm{MPa})\end{array}$ & $\begin{array}{c}\text { Ratio of PS to } \\
\text { LTS }\end{array}$ \\
\hline 0 & 16.65 & 9.68 & $55.41 \%$ \\
5 & 15.72 & 9.64 & $61.32 \%$ \\
10 & 10.81 & 7.525 & $66.53 \%$ \\
15 & 8.14 & 5.415 & $66.52 \%$ \\
\hline
\end{tabular}

direction of the maximum principal stress would have a significant impact on the stability of the coal pillar. Since the shear deformation increased with time due to the shear stress component that was induced by the inclination angle, the incremental accumulation of the shear strain could drastically shorten the time-to-failure, as seen in the test illustrated in Figure 10. Moreover, the tests results showed that the long-term strength would decrease with the increase of the inclination angle. When analyzing the stability of a coal pillar in an inclined coal seam, if the existence of the shear strain was ignored, it might therefore lead to mine disaster. Therefore, we suggested that the influence of the seam inclination on the pillar strength should be considered while designing the pillar dimensions during mining activities.

In addition, the experimental results also showed that the time-dependent deformation and the long-term strength of the specimens with an inclination angle of $5^{\circ}$ were not significantly different from those specimens under pure compression (i.e., inclination angle is $0^{\circ}$ ). It could be concluded that it was safe and feasible to design a coal pillar according to the conventional method when the inclination angle of the coal seam was less than $5^{\circ}$. The above results not only deepened the understanding of the time-dependent behavior of coal in a complex stress state but also provided a theoretical basis for a specific engineering application. However, it should be recommended that other rock types be similarly tested to gain a better understanding of the influence of a combined compression-shear load on creep behavior.

\section{Conclusions}

In this study, in order to investigate the time-dependent mechanical behavior of coal under a combined compressionshear load, a novel C-CAST system was used to carry out the creep tests. Then, a mechanical model was established, and a data processing method was proposed. The influence of the inclination angle on the peak strength, time-dependent deformation, and long-term strength of the coal specimens was analyzed. Some noteworthy conclusions are summarized as follows.

(i) The deformation and failure characteristics of coal for a quasistatic combined compression-shear loading condition were obviously different from those under pure compression. In the combined compressionshear tests, the shear deformation component increased with the inclination angle before failure. Moreover, the peak strength of the coal specimens decreased with the increase of the inclination angle as a result of the shear stress component

(ii) The pattern of the time-dependent deformation of coal in the combined compression-shear creep test was basically consistent with that of the uniaxial or triaxial compressive creep test, which included primary creep, steady creep, and tertiary creep. However, the duration of the creep before rock failure was obviously different for various compressionshear states (i.e., various inclination angles of the specimens). For the same vertical load, the larger inclined specimen was more prone to creep failure

(iii) The LTS of the coal under different compressionshear states was determined with the isochronous stress-strain method. When the inclination angle of the specimen was more than $5^{\circ}$, the LTS of the coal gradually decreased with the increase of the inclination angle. The ratio of the long-term strength to the corresponding peak strength of the coal was in the range of $61 \%-66 \%$, which indicated that the relationship between the long-term strength and the peak strength was not significantly affected by the inclination angle of the specimen

\section{Data Availability}

All the data used to support the findings of this study are included within the article.

\section{Conflicts of Interest}

There are no conflicts of interest regarding the publication of this paper.

\section{Acknowledgments}

This research was funded by the Natural Science Foundation of China (grant number 52004098) and the Science and Technology Project of Henan Province (Nos. 192102310210 and 212102310951). 


\section{References}

[1] W. J. Guo, H. L. Wang, and S. J. Chen, "Coal pillar safety and surface deformation characteristics of wide strip pillar mining in deep mine," Arabian Journal of Geosciences, vol. 9, no. 2, pp. 1-9, 2016.

[2] W. B. Zhu, J. M. Xu, J. L. Xu, D. Y. Chen, and J. X. Shi, "Piercolumn backfill mining technology for controlling surface subsidence," International Journal of Rock Mechanics and Mining Sciences, vol. 96, pp. 58-65, 2017.

[3] Z. Zheng, Z. Q. Yang, H. Z. Zhu, F. L. He, C. Y. Du, and B. Q. Liu, "Study on reasonable coal-pillar width and surroundingrock control of gob-side irregular roadway in inclined seam," Journal of Mining and Safety Engineering, vol. 36, no. 2, pp. 231-233, 2019, in Chinese.

[4] F. L. He and G. C. Zhang, "Pillar width determination and surrounding rocks control of gob-side entry with large crosssection and fully-mechanized mining," Rock and Soil Mechanics, vol. 37, no. 6, pp. 1721-1728, 2016, in Chinese.

[5] Y. Xue, Z. Z. Cao, and Z. H. Li, "Destabilization mechanism and energy evolution of coal pillar in rockburst disaster," Arabian Journal of Geosciences, vol. 13, no. 13, pp. 1-13, 2020.

[6] Q. Y. He, Y. C. Li, B. J. Zhou, B. Y. Wu, X. W. Zhang, and S. Zhang, "Mechanical properties of granite under quasistatic compression combined shear loading," Journal of Mining and Safety Engineering, vol. 37, no. 3, pp. 162-169, 2020, in Chinese.

[7] Y. Xue, J. Liu, P. G. Ranjith, X. Liang, and S. Wang, "Investigation of the influence of gas fracturing on fracturing characteristics of coal mass and gas extraction efficiency based on a multi-physical field model," Journal of Petroleum Science and Engineering, vol. 206, article 109018, 2021.

[8] Q. L. Yao, Q. Hao, X. Y. Chen, B. J. Zhou, and J. Fang, "Design on the width of coal pillar dam in coal mine groundwater reservoir," Journal of China Coal Society, vol. 44, no. 3, pp. 890898, 2019.

[9] Y. Zhang, F. Ren, and X. Zhao, "Characterization of joint set effect on rock pillars using synthetic rock mass numerical method," International journal of geomechanics, vol. 17, no. 3, article 06016026, 2017.

[10] Q. Y. He, Y. C. Li, J. H. Xu, and C. G. Zhang, "Prediction of mechanical properties of igneous rocks under combined compression and shear loading through statistical analysis," Rock Mechanics and Rock Engineering, vol. 53, no. 2, pp. 841-859, 2020.

[11] L. Chen, X. B. Mao, and P. Wu, "Effect of high temperature and inclination angle on mechanical properties and fracture behavior of granite at low strain rate," Sustainability, vol. 12, no. 3, article 1255, p. 25, 2020.

[12] Q. Y. He, Y. C. Li, and S. She, "Mechanical properties of basalt specimens under combined compression and shear loading at low strain rates," Rock Mechanics and Rock Engineering, vol. 52, no. 10, pp. 4101-4112, 2019.

[13] F. Suorineni, P. Kaiser, J. J. Mgumbwa, and D. Thibodeau, "mining of orebodies under shear loading part 1-case histories," Mining Technology, vol. 120, no. 3, pp. 137-147, 2011.

[14] W. G. Pariseau, "Shear stability of mine pillars in dipping seams," in The 23rd U.S. Symposium on Rock Mechanics (USRMS), American Rock Mechanics Association, 1982.

[15] M. Foroughi and V. Vutukuri, Estimating elastic pillar stresses in inclined coal seams, vol. 302, Transactions of Society for Mining, Metallurgy, and Exploration, Inc, 1997.
[16] S. J. Chen, W. J. Guo, G. Q. Cheng, and T. P. Zhao, "Research on creep supporting effect of deep strip pillar," Journal of Mining and Safety Engineering, vol. 29, no. 1, pp. 52-57, 2012, in Chinese.

[17] Y. J. Yang, H. Q. Duan, C. X. Liu, and Y. R. Hao, "Reasonable design of coal barrier pillar of roadway in deep mining considering long-term stability," Journal of Mining and Safety Engineering, vol. 34, no. 5, pp. 921-927, 2017, in Chinese.

[18] A. Sainoki and H. S. Mitri, "Numerical investigation into pillar failure induced by time-dependent skin degradation," International Journal of Mining Science and Technology, vol. 27, no. 4, pp. 591-597, 2017.

[19] H. B. Zhao, G. Z. Yin, and W. Z. Zhang, "Study of creep characteristics and constitutive relation of briquette under confining pressure," Rock and Soil Mechanics, vol. 30, no. 8, pp. 2305-2308, 2009, in Chinese.

[20] T. T. Cai, Z. T. Feng, D. Zhao, and Y. L. Jiang, "A creep model for lean coal based on hardening-damage mechanism," Rock and Soil Mechanics, vol. 39, no. s1, pp. 61-68, 2018, in Chinese.

[21] S. Q. Yang, P. Xu, and P. G. Ranjith, "Damage model of coal under creep and triaxial compression," International Journal of Rock Mechanics and Mining Sciences, vol. 80, pp. 337-345, 2015.

[22] H. B. du, F. Dai, Y. Xu, Z. L. Yan, and M. D. Wei, "Mechanical responses and failure mechanism of hydrostatically pressurized rocks under combined compression-shear impacting," International Journal of Mechanical Sciences, vol. 165, article 105219, 2020.

[23] Y. Xu and F. Dai, "Dynamic response and failure mechanism of brittle rocks under combined compression-shear loading experiments," Rock Mechanics Rock Engineering, vol. 51, no. 3, pp. 747-764, 2018.

[24] Ö. Aydan, T. Ito, U. Özbay et al., "ISRM suggested methods for determining the creep characteristics of rock," Rock Mechanics and Rock Engineering, vol. 47, no. 1, pp. 275-290, 2014.

[25] X. L. Xu, R. Zhang, F. Dai, B. Yu, M. Z. Gao, and Y. F. Zhang, "Effect of coal and rock characteristics on ultrasonic velocity," Journal of China Coal Society, vol. 40, no. 4, pp. 793-800, 2015.

[26] X. H. Liu, Q. J. Hao, S. Y. Wu, R. Zhang, and J. Yu, "Nonlinear mechanical properties of coal rock under quasi-static strain rate," Journal of China Coal Society, vol. 44, no. 5, pp. 14451473, 2019.

[27] R. B. Hou, K. Zhang, J. Tao, X. R. Xue, and Y. L. Chen, “A nonlinear creep damage coupled model for rock considering the effect of initial damage," Rock Mechanics and Rock Engineering, vol. 52, no. 5, pp. 1275-1285, 2019.

[28] Y. J. Song, Y. X. Che, L. T. Zhang, J. X. Ren, S. J. Chen, and M. L. Hu, "Triaxial creep behavior of red sandstone in freeze-thaw environments," Geofluids, vol. 2020, Article ID 6641377, 20 pages, 2020.

[29] Z. W. Zhou, W. Ma, S. J. Zhang, C. Cai, Y. H. Mu, and G. Y. Li, "Damage evolution and recrystallization enhancement of frozen loess," International Journal of Damage Mechanics, vol. 27, no. 8, pp. 1131-1155, 2018.

[30] N. A. Chandler, "Quantifying long-term strength and rock damage properties from plots of shear strain versus volume strain," International Journal of Rock Mechanics and Mining Sciences, vol. 59, pp. 105-110, 2013.

[31] L. Jian-feng, W. Lu, P. Jian-liang, Z. Lu, and B. Yu, "Experimental study on creep deformation and long-term strength of unloading-fractured marble," European Journal of 
Environmental and Civil Engineering, vol. 19, supplement 1, pp. s97-s107, 2015.

[32] Y. Zhang, P. J. Jin, W. Y. Xu, H. B. Zhao, and S. H. Mei, “Experimental study of triaxial creep behavior and long-term strength of clastic rock in dam foundation," Rock and Soil Mechanics, vol. 37, no. 5, pp. 1291-1300, 2016, in Chinese.

[33] M. R. Shen and H. J. Chen, "Testing study of long-term strength characteristics of red sandstone," Rock and Soil Mechanics, vol. 32, pp. 3301-3305, 2011.

[34] L. Cong and X. L. Hu, "Triaxial rheological property of sandstone under low confining pressure," Engineering Geology, vol. 231, pp. 45-55, 2017.

[35] Z. W. Zhou, W. Ma, S. J. Zhang, H. M. Du, Y. H. Mu, and G. Y. Li, "Multiaxial creep of frozen loess," Mechanics of Materials, vol. 95, pp. 172-191, 2016.

[36] R. B. Hou, K. Zhang, and J. Tao, "Effects of initial damage on time-dependent behavior of sandstone in uniaxial compressive creep test," Archives of Mining Sciences, vol. 64, no. 4, pp. 687707, 2019.

[37] T. Tan, "The mechanical problems for the long-term stability of underground galleries," Chinese Journal of Rock Mechanics and Engineering, vol. 1, pp. 1-20, 1982. 